\title{
The Vocabulary Profile of UN (Ujian Nasional) Reading Texts of Senior High School
}

\author{
Andila Atmadja \\ Universitas Katolik Atma Jaya Jakarta \\ andila.atmadja@gmail.com
}

\begin{abstract}
This study was aimed at investigating the vocabulary profile of English UN 2015 Reading Texts for Senior High School. Content analysis was used as a research method. The data were vocabularies which encountered within 14 reading texts. The instruments were Lewis (1997) divisions of lexical items adapted in Lakshmi (2012) and 10003000 new general service list by Browne and Coxhead (2013) within Vocab Profiler software inventing by Cobb (2009). The result showed that (1) There were four lexical items encountered in the UN 2015 Reading Text. They were: polywords, collocation, a fixed expression, and semi-fixed expression. (2) The most dominant of lexical items were encountered in the Reading Text is collocation with 145 words (60\%), Polywords with 51 words (21\%), Semi fixed expression with 38 words (16\%) and the lowest was fixed expression with 7 words (3\%). (3) There were 1067 words (88\%) in the UN reading text were the extent of coverage level 1000-3000 NGSL and NAWL level by Browne and Coxhead. The conclusion was the teacher should teach the students about collocation and other word partnership to assist students to comprehend the English text better
\end{abstract}

Keywords: Vocabulary, lexical items, vocabulary level

\section{INTRODUCTION}

In the process of teaching language, especially English, one of the basic aspects essential to the students' knowledge is lexis. Richard and Rodgers (2001) suggest that the component of language learning and communication is lexis, that is word and word combination not notion, grammar, function or some other elements of planning and teaching. A 
lexeme is the central unit of the lexicon of a language. A lexeme is a unit that may consist of one or more (orthographic) word form; simple containing single words and complex being multi-word expressions. A lexeme correlates with words because the words are derived from lexeme. For example, the word walk, walks and walking and walked are forms of the lexeme 'walk'.

Vocabulary denotes to the words and phrases that individuals know and use. It contains an understanding of how words synergy within specific contexts. Vocabulary is concerned with meaning. While someone gets older their vocabulary develops and it also serves as a beneficial and essential device for communication and attaining knowledge. Acquiring a wide-ranging vocabulary is one of the prime tasks in learning a second language. "Vocabulary is a clear indicator of how well foreign language (FL) learners can communicate" (Lewis, 1997). Speaking of learning a language, there are four skills that the learner needed to be mastered, that is: listening, reading, speaking and writing. Having vocabulary knowledge is essential since one cannot comprehend a sentence if the most of the words are unknown. Besides, students' word knowledge is connected greatly for being successful in academic since students who have a wide-ranging vocabulary can comprehend new ideas and concepts more swiftly than students with inadequate vocabulary knowledge. Lacking vocabulary knowledge impact the four skills of the language. Therefore, vocabulary is important to be mastered in learning a second language.

Ujian Nasional (UN) was first held in Indonesia in 1985 for four cores of subjects such as mathematics, science, Indonesian language, and English. The aims of its management are first to map the quality of education service across regions and secondly to set a criterion for graduation. "Increasing the quality of education is very important because it's related to human resource quality" quoted Zakaria (2009) a member of Badan Standar Nasional Pendidikan (BSNP).

UN becomes one of the scariest moments for students in Indonesia. In English subject to be more specific, despite changes in curriculum approach, reading has been the dominant skill tested and reading text is one of the problems for students in accomplishing their English test. Students' lack of vocabulary makes them difficult to comprehend the overall meaning of English Reading text. As stated by Meara (1980) deficiency of adequate vocabulary knowledge is a noticeable and solemn problem for many students who learn English as a second language. Learners themselves willingly confess that they face 
many difficulties with vocabulary, and most learners find that attaining vocabulary as their utmost single basis of difficulties.

Moreover, Laufer (1989) points out that a successful comprehension involves more than being able to understand vocabulary in a text, and a lack of familiarity with more than $5 \%$ of the running words in a text can make reading a formidable task. Considering these conditions, the writer is interested in conducting research related to the vocabulary profile of the UN (Ujian Nasional). To conduct this study, the writer focuses on investigating the vocabulary profile of reading texts of the UN 2015 English Exam for Senior High Schools. There was 14 reading text in English Exam. In this study, the writer will focus on the types of lexical items met in UN 2015 reading-text, each frequency of the lexical items, and the vocabulary the extent of UN reading texts for Senior High schools that covered 3000 new general service list and new academic words list by Browne and Coxhead.

This study was intended to investigate the vocabulary of UN 2015 English reading texts for Senior High Schools, which part that mostly dominant and which part that should be pay more attention. The purpose of this study can be achieved by finding out the types of lexical items encountered in UN 2015 reading texts, finding out the frequency of each lexical items, and finding out the extent of vocabularies of UN 2015 reading texts for Senior High Schools that cover the 1000 - 3000 level new general service list and new academic words list by Browne and Coxhead (2013).

Based on the background above, the question of this study is formulated into three research questions as follows: What are the types of lexical items encountered in the UN 2015 reading text? What is the frequency of each lexical item? To what extent do the vocabularies of UN reading texts for Senior High schools cover the 1000 - 3000 level new general service list and new academic-word list by Browne and Coxhead?

\section{THEORITICAL FRAMEWORK}

\section{Vocabulary and Lexis}

Vocabulary denotes to a set of words for a certain language that specific utterers of language might use (Hatch, 1995). Lewis (1993) states that "lexis refers to strings of words that go together". Lexis contains words and words combinations that persons hoard in their mental lexicons (Olga, 2001).

The differences between vocabulary and lexis are that the term vocabulary denotes to words alone, while Lexis relates to not just words 
but elements both above and below the word level, smaller elements such as particles ('down' in the phrasal verb step down) including bound morphemes ('im' as in impossible) in addition to larger elements such as fixed expressions (call it a day, by the way). Vocabulary is invented of the word units themselves. It contains the word units only, while lexis denotes to the structure of word units in a language. It is a central point that lexis comprises a system primarily as lexis interfaces with other features of language.

\section{Lexical items}

Lexical item is a single word or chunk of a word or a chain of words that build the fundamental elements of a language lexicon (vocabulary). Lewis (1997) proposes lexical items to be divided into four types as follow: words and polywords, collocation, fixed expression, and semifixed expression

\section{Words and Polywors}

Words constitute the largest of all four categories. They refer to words that can stand alone and what we traditionally call vocabulary. E.g. open, sit. While Polywords denotes to a small set of lexical items that place between words and main multi-word clusters. Lewis (1997) reflects adverbial phrases of different categories such as polywords. e.g sentence adverbs: in contrast, expressions of time: yesterday, next week, today, prepositions of place: around the corner.

\section{Collocations}

Collocations are lumps of lexical items that indeed co-occur by common expectancy. Kjellmer (1987) defines collocation as a system of words that befalls more than once in the same form in the corpus, that is grammatically well organized. Similarly, Clear (1993) suggests that collocation is a recurrent co-occurrence of words. Lewis (2000) suggests different kinds of collocations as follows: • Adjective + Noun $=$ mysterious circumstance $\cdot$ Noun + Noun $=$ variety show $\cdot$ Verb + Adjective + Noun $=$ have a better plan $\cdot$ Verb + Adverb $=$ sing beautifully $\cdot$ Adverb + Verb $=$ well paid $\cdot$ Adverb + Adjective $=$ obviously sick $\cdot$ Verb + preposition + Noun $=$ reconcile with the past.

\section{Fixed Expression}

Fixed expressions or Institutionalized expressions are chunking a speaker provision as components and uses in speech. E.g - Social Greetings: Good afternoon; How's life? · Politeness Phrases: Sure, I'm good. Phrase Book Language: Can you pass me the sauce Please? Idioms: break a leg. 


\section{Semi-Fixed Expression}

According to Lewis (1997), "semi-fixed expressions are often verbless expressions in the spoken language for managing the everyday situation". He categorized semi-fixed expression into several categories: Almost-fixed expressions, which allow minimal variations: isn't/ That's not my type - Spoken sentences with a simple space: Can you give ........, please? • Expressions with a space that must be filled with a particular kind of slot-filler: Hi. Glad to see you. I haven't seen you + time expressions with for or since. Sentence heads, which can be finished in many ways: What was fascinating /shocking/irritating was........ More prolonged frames such a formal letter or the introductory paragraph of an academic paper. For example, I'm writing to apply ... Today trends cannot be separated by ...(Lewis,1997).

\section{Vocabulary Level}

On the 60th anniversary of Michael West's publication of the General Service Lists (GSL) in 2013, Philips and Browne publicized the formation of a New General Service List (NGSL), one that is created by a prudently selected 273 million-word subsection of the 2 billion-word Cambridge English Corpus (CEC). Also, Browne and Coxhead (2013) worked to create a New Academic Word List (NAWL) to complement students and teachers working with the NGSL who wanted to learn or teach academic English. The combination of NGSL/NAWL bestows approximately 5\% more text coverage than the collective GSL/AWL.

Nunan (2003) proposes that there are three types of vocabulary; academic 2 high frequency and low frequency. Academic vocabulary refers to words that are more often found in academic texts than in any other form of text. The high-frequency words are the 2000 most commonly used words within a language. Low-frequency vocabulary words are the other words that are not in the 2000 high frequency.

Nation (2012) advocates that it is beneficial to see vocabulary distinguished into three main levels. High-frequency vocabulary of about 2000 words, a mid-frequency vocabulary of an supplementary 7000 words creating a sum of 9000 and the lasting low-frequency vocabulary of at least another 10000 words or possibly higher._Adult native speakers appear to have a vocabulary size of about 20000 words, nonetheless mastering this would be a very long-standing goal for most foreign language learners. More practical goals are to object primarily at a high-frequency vocabulary of 2000 words, and to give notice greatly to 
the most advantageous portion of the mid-frequency vocabulary for certain determinations.

Hsu (2009) states "to pass the senior high school examination a student has to have a vocabulary size of at least 2000 words". Besides, Hatch (1995) states that High School students learning English in Spain are familiarized to 800-1,000 English words in their first grade of EFL class, 1,700-2,000 more in second grade, and 2,500-3,000 in the third grade. Hence, it can be inferred that to pass the examination, students of Senior High Schools have to master at least 1000 - 3000 words.

\section{English Reading text in the UN}

Reading is a procedure conducted by readers to obtain information from the author of the text. Through reading, the students can broaden and hone their point of view based on their knowledge. Nonetheless, it is quite hard to persuade students that the texts in English can be comprehended although there are some vocabularies and structures that the students have never met previously. In short, it can be concluded that reading in a foreign language involves of understanding the meaning in that language over its written illustration (Lado, 1961). From the description mentioned previously, we can obtain valuable information which is used in daily basis. For instance, reading a billboard, tabloid, story, and many more.

Reading is one of the best ways of expanding vocabulary. Cunningham (2001) noted that (1) vocabulary should be trained both directly and indirectly; (2) recurrence and numerous exposures to vocabulary items are significant; (3) learning in amusing contexts is treasured for vocabulary learning; (4) how vocabulary is measured and calculated can have differential effects on instructions; and (5) depending on only vocabulary - learning strategy will not result in best learning.

UN turn out to be the government device to evaluate how Indonesia's education system works. The results of UN can be used to display whether the government has controlled Indonesia's education properly or not. Stated in government regulation number 19 the year 2005 on national education standard that the function of the UN is as follows: 1 . Mapping school quality; 2. Selection criteria to enter higher education; 3 student graduation criteria; 4 developing and giving aid to schools to improve the quality of education. Moreover, the minimum passing grade standard for all subjects in the UN 2015 for Senior High School is 5.5 from the scale 1-10. Simply spoken, it can be said that if students' 
achievement is good or at least reach the standard, the government is successful.

In this case, understanding the vocabulary in English reading text in the UN is important. The relationship between UN reading comprehension text, lexical items and vocabulary cannot be separated. The roles of vocabulary and lexical items are important in reading comprehension because to understand the whole text, the learners need to have a wide extent of vocabulary and besides that, the text can be understood not only on the single-word basis but also in multi-word expressions such as phrases, clauses, and sentences as its building blocks.

\section{RESEARCH METHODOLOGY}

This study utilized qualitative research by using content analysis as a research method. This study was conducted from February to June 2016 in Jakarta. The data of this study were the vocabularies which encountered within 14 reading texts. The subject of this study was English UN reading text 2015 for Senior High School. The vocabularies were investigated to analyze the vocabulary profile of English UN reading text 2015 by finding out the types of lexical items, the frequency of each lexical items and to what extent do the vocabularies can cover 1000 - 3000 level new general service list and new academic word-level within each text in reading the text.

There were 5 types of English UN Exam test packages. each package of which carried equal exam weightings, as stated by BNSP in its released for the prediction of English UN text. The writer used only one package of UN 2015 English exam tests for the Science program, taken from SMAN 22 Jakarta as the data source.

The instrument of this study was Lewis' (1997) concept of lexical items adapted by Laksmi's (2012) study to investigate the vocabulary profile of English UN reading text 2015 and 1000 - 3000 level new general service list and new academic words lists by Browne and Coxhead (2013) within Vocab Profiler software inventing by Cobb (2009).

In this study, the data were collected in some steps, such follows:

1. Taking one package sample out of five packages of UN English Test 2015 for Senior High School.

2. Reducing the part of data that do not belong to the study. The data were reduced by excluding the listening section, question and several words such as follows: such as proper noun, 
interjections, unclassified words, alphabetical symbols, units, and abbreviations from this study. Those words were excluded to prevent inflated vocabulary size and shrink text coverage.

The data were analyzed in some steps, such follows:

1. Classifying he reading texts using Lewis' (1997) theory of lexical items/ chunks divisions adapted by Lakshmi (2012) which fall into four parts polywords, collocation, fixed expression, and semi-fixed expression as presented in the table below.

2. The writer divided the lexical items into four parts polywords, collocation, fixed expression, and semi-fixed expression of reading texts and labeled and separated each division of lexical items in an individual table to make it specific and easy for analysis before inputting it in the table of lexical items.

3. Polywords type is the first type of lexical items. It consists of the expression of time, sentence adverb, phrasal verbs and preposition of place.

4. Collocation is the second type of lexical items. Collocation is a sequence of words that occurs more than once in an identical form. In his research Lewis (2000) divides different kinds of collocation into twelve parts. It consists of Adjective + Noun, Verb + Noun, Noun + Noun, Noun + Verb, Noun + Preposition, Verb + Adjective, Adverb + Adjective, Adjective + Preposition, Adverb + Verb, Verb + Preposition and Verb + Adverb.

5. Fixed expression is chunk a speaker stores as units and uses in speech. Fixed expression is divided into one-worded, twoworded, three-worded, four-worded, and five-worded.

6. Semi fixed expression is often verbless expressions in the spoken language for managing everyday situations. It consists of sentence head, discourse markers, and sequencers.

7. Calculating the types of lexical items which mostly occurred in the text. To see its frequency.

8. Calculating the total number of words appearing using Browne and Coxhead 1000-3000 New General Service Lists within Vocab Profiler software (www.lextutor.ca) inventing by Cobb (2009) to find out the vocabulary extent of English UN 2015 Reading Texts.

9. Summarizing the result of the study into tables and charts in finding and conclusion. 
This study used Lewis's (1997) theory of types of lexical items/ chunk divisions that had been adapted in Lakshmi (2012) and Browne and Coxhead (2013) 1000-3000 New General Service Lists within Vocab Profiler software (www.lextutor.ca) invented by Cobb (2009) as the analysis criteria.

\section{FINDINGS}

In this study, the writer analyzed the vocabulary profile of UN 2015 Reading Text for Senior High School. This chapter was organized based on the research questions as previously mentioned in chapter I

\section{Types of the lexical items encountered in English UN 2015 Reading Texts}

From the 14 UN 2015 reading texts, the writer classified the vocabulary based on Michael Lewis (1997) concept of lexical items. The concept categorized lexical items into four division: Polywords, collocation, fixed expression (institutionalized expression) and semi fixed expression.

After analyzing each subdivision of lexical items -- polywords, collocation, fixed expression and semi-fixed expression, the writer summarized the types of lexical items encountered in the UN reading texts as in the table 1.

Table 1.

Types of the lexical items encountered in English UN 2015 Reading Texts

\begin{tabular}{|l|l|l|l|l|l|l|l|l|l|}
\hline $\mathbf{T}$ & $\mathbf{P}$ & $\mathbf{C}$ & $\mathbf{F E}$ & $\mathbf{S F E}$ & $\mathbf{T}$ & $\mathbf{P}$ & $\mathbf{C}$ & $\mathbf{F E}$ & $\mathbf{S F E}$ \\
\hline $\mathbf{1}$ & 3 & 8 & 2 & 2 & $\mathbf{8}$ & 4 & 16 & 2 & 1 \\
\hline $\mathbf{2}$ & 2 & 3 & 1 & - & $\mathbf{9}$ & 3 & 12 & - & 5 \\
\hline $\mathbf{3}$ & 4 & 16 & - & 1 & $\mathbf{1 0}$ & 7 & 26 & - & 3 \\
\hline $\mathbf{4}$ & 5 & 13 & - & 5 & $\mathbf{1 1}$ & 1 & 9 & - & 1 \\
\hline $\mathbf{5}$ & 10 & 13 & - & 5 & $\mathbf{1 2}$ & 2 & 8 & - & 5 \\
\hline $\mathbf{6}$ & 7 & 5 & 1 & 5 & $\mathbf{1 3}$ & - & 3 & - & 1 \\
\hline $\mathbf{7}$ & 2 & 11 & 1 & 3 & $\mathbf{1 4}$ & 1 & 4 & - & 1 \\
\hline Tot & 34 & 69 & 5 & 21 & Tot & 18 & 78 & 2 & 17 \\
\hline
\end{tabular}

Note:

T : Text

P : Polywords

C : Collocations

FE : Fixed Expression SFE : Semi Fixed Expression Tot : Total Grand Tot : Grand Total 


\begin{tabular}{|l|l|l|l|l|}
\hline Grand tot & $\mathrm{P}=51$ & $\mathrm{C}=147$ & $\mathrm{FE}=7$ & $\mathrm{SFE}=38$ \\
\hline
\end{tabular}

Viewing the results of the table above, there were four lexical items were encountered in UN 2015 Reading Text. They were polywords, collocation, fixed expression and semi fixed expression (see appendix 2). However, in text 13, there are no polywords. In text 3 to 5 and 10 to 14 there are no fixed expressions, as well as no semi-fixed expressions in the text 2 . This result showed that fixed expression was the least type encountered in the reading text.

To see the specific analysis of this study, the writer showed each subdivisions chart of the lexical items as follows:

According to Lewis (1997) Polywords referred to a small group of lexical items which falls between words and major multi-word categories. The writer found fifty-five polywords from the UN Reading Texts selected for this study. The polywords were subdivided into four categories namely expression of time, sentence adverbs, phrasal verbs, and preposition of place.



Chart 1 : Polywords Analysis

After analyzing the text, the writer found 17 phrasal verbs (34\%), 14 expressions of time (28\%), 13 preposition of place (26\%), and 6 sentence adverbs (12\%). 
Lewis defined collocation as the readily observable phenomenon whether certain words co-occur in natural text with greater than random frequency. In this study, there were one hundred and forty-five collocation identified from UN 2015 Reading Text chosen for the study.

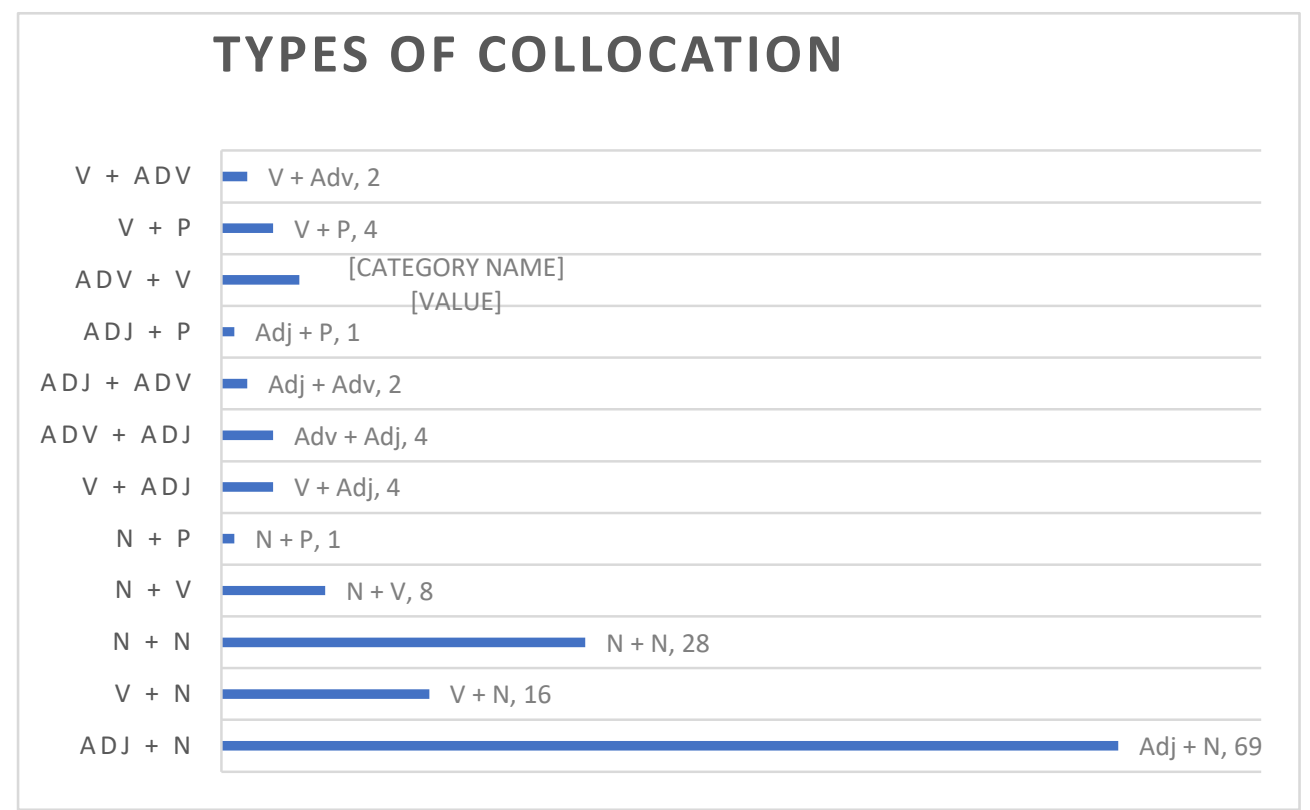

\section{Chart 2 : Collocation Analysis}

The writer found 69 adjective+noun (48\%), 16 verb+noun (11\%), 28 noun+noun (19\%), 8 noun+verb (5\%), 1 noun+preposition (1\%), 4 verb+adjective (3\%), 4 adverb+adjective(3\%), 2 adjective+adverb(1\%), 1 adjective+preposition (1\%), 6 adverb+verb (4\%), 4 verb+preposition (3\%), 2 verb+adverb(1\%).

According to Lewis (1997) Fixed expression or institutionalized expressions are chunks a speaker stores as units and uses in speech. The writer identified seven fixed expression from the UN reading texts selected for this study. The fixed expressions were classified into five categories: one-worded, two-worded, three-worded, four-worded and five-worded. 


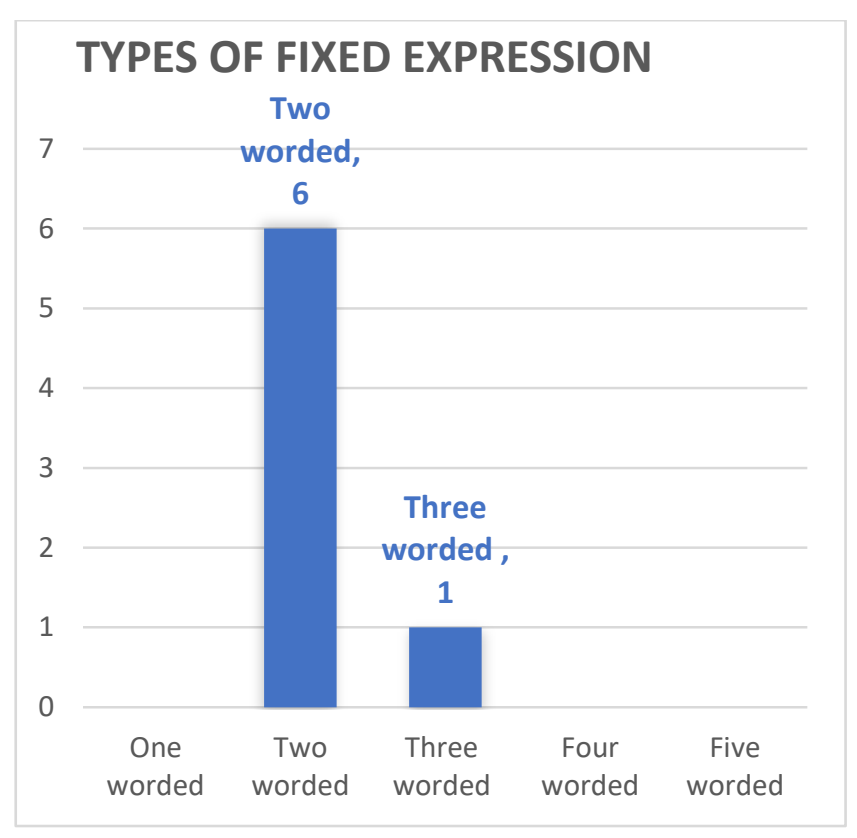

Chart 3: Fixed Expression

The writer identified 6 two worded (86\%) and 1 three worded (14\%). According to Lewis (1997) semi-fixed expression are often verb less expressions in the spoken language for managing everyday situations'. The writer identified thirty eight semi fixed expression from the UN Reading Texts selected for this study. The present study only found two broad categories namely sentence head and other semi-fixed expression which include discourse markers and sequencers. Sentence head was referred to those clauses or phrases that allowed a substitution in their place and which provided a chance to the speaker to complete them in many ways. Discourse markers were words which connect what was being expressed and what follows next in the spoken and written language. Sequencers too are a type of discourse markers that highlight the order of the happenings. 




Chart 4: Semi Fixed Expression

The writer identified 18 sentence heads (47\%), 13 discourse markers (35\%), and 7 sequencers (18\%).

The frequency of each lexical items in English UN 2015 Reading Texts

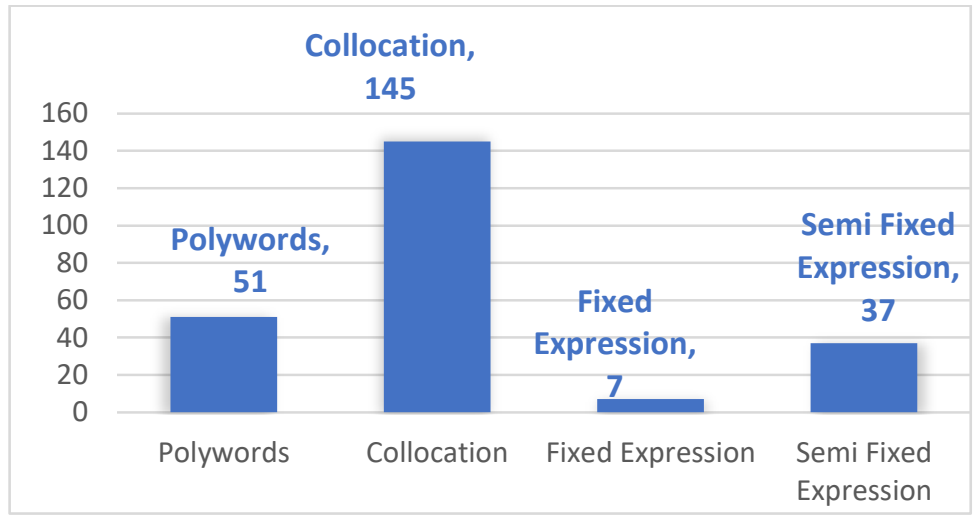

Chart 5: The frequency of each lexical items

Based on the chart above the most dominant of lexical items in the UN Reading Text was collocation with 145 words (60\%), followed by Polywords with 51 words (21\%), semi fixed expression with 38 words $(16 \%)$ and the lowest was fixed expression with 7 words $(3 \%)$. From the chart of lexical items frequency above, it can be seen that collocation is the most important part in reading, because every paragraph in the texts consists of some collocations, especially the adj+n part. Therefore, it is obvious that it is important to understand this word partnership to comprehend the reading text in UN. 
The extent of vocabularies in English UN 2015 Text that covered 1000-3000 New General Service List and New Academic Words List.

Based on theory of Hsu (2009) in order to pass the senior high school examination the students had to master vocabulary size of at least 2000 - 3000 words. In this part, the writer showed the results of total number of words appeared in 3000 vocabulary list in UN 2015 Reading Texts for Senior High School using Charles and Browne (2013) 3000 level vocabulary lists as its parameter. The chart were presented below:

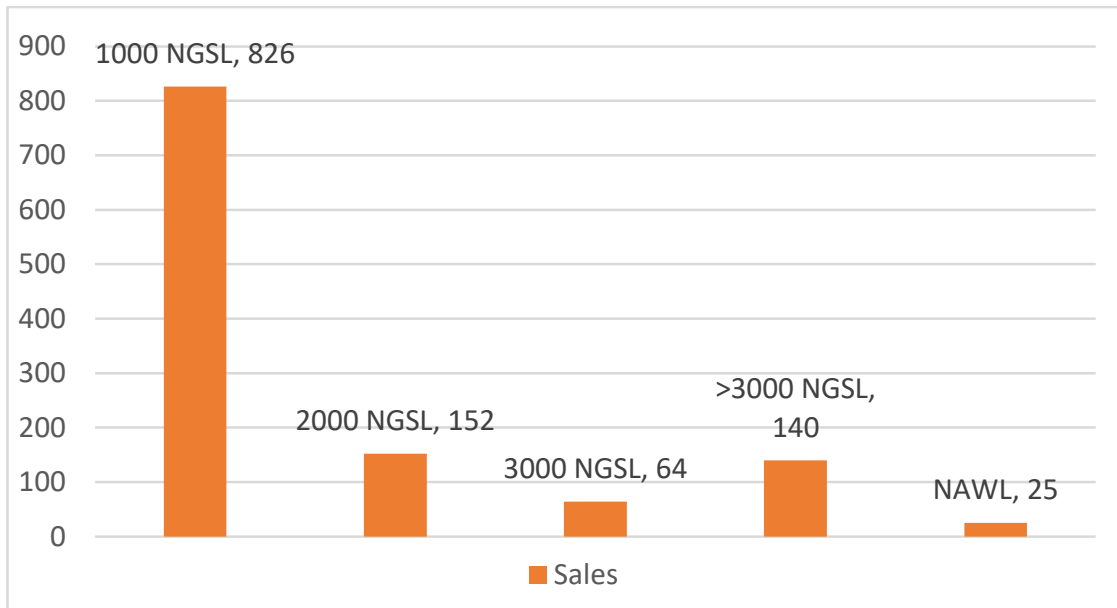

\section{Chart 6: The Extent of Vocabularies in English UN 2015 Reading Texts covered NGSL and NAWL}

Based on the table and chart above, the results showed that the most dominant words appearing in the texts fall into the 1000 NGSL comprising 826 words (68\%), followed by 2000 NGSL with 152 words (13\%), then $>3000$ NGSL with 145 words, 3000 NGSL with 64 words (5\%) and the last NAWL with 25 words (2\%). From the chart above it can be seen that the English UN 2015 reading texts for Senior High Schools contained of 1067 words or $88 \%$ in the vocabulary extent of 1000 NGSL to 3000 NGSL and NAWL level. However, it would be better if the teacher and students also study the vocabulary beyond 3000 level because the percentage of vocabulary $>3000$ level occupied the thirdrank dominant words in the UN texts. 


\section{DISCUSSIONS}

Based on the analysis above, the writer discussed three points. First, the writer talked about the types of lexical items encountered in the reading text. Second, the frequency of each lexical items in the reading text and the last, the extent of vocabularies in English UN 2015 Text that covered NGSL and NAWL.

In the category of the lexical item, there were four types of lexical items were encountered in UN 2015 Reading Text. They were polywords, collocation, fixed expression, and semi-fixed expression. The results showed that most of the words encountered in the texts were collocation and polywords. However, in several texts, there were no fixed expressions and only some semi-fixed expressions identified. Since the most text contained of collocation and polywords, it can be concluded that students should be a concern and study more about collocation.

This result also supported by Rao (2018) who asserted that collocations were very significant part of knowledge of second language acquisition and they were essential to non-native speaker of English. As non-native speaker of English Indonesian's students should recognize collocation and its word partnership because it was significant to understand the UN reading text not only content of the vocabulary words which can stand alone but also the group of words which make a building blocks of sentences and text such as collocation and polywords. Rao (2018) also added in his study that both teacher and student should pay more attention to collocations and be aware of its acquisition of a word. This argument is making sense, since some English words and sentences cannot be translated one by one but at least in a phrase to make it meaningful. Therefore, learning and reading more about how the lexical items and its types in the reading text are important for both teacher and students to comprehend the reading texts in the UN better.

Next was the frequency of lexical items, in this section, the writer found that in lexical items chart, collocation was the dominant parts of lexical items that were encountered. In this part, the results showed that the dominant parts in collocation subdivision were adj + noun, and the subdivision of polywords that were dominant in this text were phrasal verbs. Collocation and polywords build phrases and clauses. Phrases and clauses themselves are the second and third grammatical hierarchies afterwords. Before a reading text becomes a whole text, the text consists of words, phrases, clauses, and sentences. Thus, the students should learn more about collocation and polywords because they build phrases 
and clauses that carry meaning to understand the content contexts within the texts.

The last was 1000-3000 vocabulary lists. The finding showed that most of the vocabulary words in English UN 2015 reading text were covered in the vocabulary extent of the 1000-3000 vocabulary list by Browne and Coxhead (2013). The results showed that the UN 2015 English reading texts for Senior High Schools were 88\% in the vocabulary extent of 1000 NGSL to 3000 NGSL level. As Hsu (2009) stated that to pass the senior high school examination students had to master the vocabulary size of at least 2000 words. Besides, Hatch (1995) noted that High School students studying English are introduced to 8001,000 English words in a first-year EFL class, 1,700-2,000 more in second-year classes, and another 2,500-3,000 in the third year. Thus, it can be concluded that to pass the examination students in Senior High School have to master at least 1000 - 3000 words and that theory align the results of this present study which was the UN 2015 reading texts in Senior High School were extent 88\% vocabulary from 1000 NGSL to 3000 NGSL and NAWL level. However, it would be better if the teacher and students study the vocabulary beyond 3000 level because the percentage of vocabulary $>3000$ levels occupy the third rank dominant words in the UN text.

In the end, the teacher should help the students to find out what kind of vocabulary that they should know to accord their level because Senior High School is crucial. Senior High School is the gate to the university level, and the candidate students of the university are demanded to know at least 1000-3000 level of vocabulary to pass senior high school successfully before they enter higher education in the university. Thus, it's important for teacher to help the students to find out what kind of vocabulary that they should know to accord their standard level.

\section{Conclusion}

In conclusion, firstly, the study revealed that there were four lexical items encountered in UN 2015 Reading Texts. Among those four, the reading texts were dominated by collocation and polywords, rather than fixed expressions and semi-fixed expressions. Therefore, students should be aware and pay more attention on learning collocation and polywords to comprehend the reading texts in the UN better. Secondly, the frequency of lexical items in this study was dominated by collocations. Hence, collocation is the most important element in reading text. As every paragraph in the texts mostly contain collocations, this 
could be the evidence that shows this word partnership is important to be mastered in comprehending the UN reading texts. Thirdly, there were 1067 words (88\%) in the UN reading text were covered of coverage level of 1000 to 3000 New General Service Lists and New Academic Words Lists level by Browne and Coxhead. As Hsu (2009) and Hatch (1995) theories state that to pass the exam successfully students in Senior High Schools have to master at least 1000-3000 words, that theory accords with the results of this present study in which the UN 2015 reading texts in Senior High Schools covered 88\% vocabulary from 1000 NGSL to 3000 NGSL and NAWL level.

\section{SUGGESTIONS}

There are several aspects that the writer wants to suggest. To understand a text as a whole, it would be easier if the students learn how to comprehend the group of words in grasping the content meaning within the texts by guessing from the context, rather than by translating the words one by one.

Unfortunately, learning collocations seems not take into account by some teachers especially non-native teacher in non-English speaking country such as Indonesia. As they just focus on surface meaning vocabulary itself without break down how complex the vocabulary it could be if they do not translate it in a correct way. Accordingly, the teacher should teach the students collocation and other word partnerships or word combinations, to assist students in comprehending the English sentences better and more meaningful in the future.

The students' lack of vocabulary and vocabulary mastery can be fixed and enriched by asking them to read more, not only textbooks but also authentic materials such as English magazines, newspaper, and novels; and try to use the new vocabularies in their daily conversations so that the vocabularies stay on their long-term memory.

\section{REFERENCES}

Bowey, J. A. (2005). Predicting individual differences in learning to read. The science of reading: A handbook, 155-172.

Browne, C., Culligan, B., \& Phillips, J. (2013). The new general service list: A core vocabulary for EFL students and teachers.JALT's The Language Teacher, 34(7), 13-15. 
Cobb, T. (2007). Computing the vocabulary demands of L2 reading. Language Learning \& Technology, 11(3), 38-63.

Coxhead, A. (2000). A new academic word list. TESOL quarterly, 34(2), 213-238.

Cunningham, J. W. (2001). The national reading panel report. Reading Research Quarterly, 36(3), 326-335.

Fromkin, V., \& Rodman, R. Hyams,(2007). An introduction to language, 8th ed. Boston: Thomson Wadsworth.

Hatch, E., \& Brown, C. (1995). Vocabulary, Semantics, and Language Education. Cambridge University Press, 40 West 20th Street, New York, NY 10011-4211 (hardback: ISBN-0-521-47409-4; paperback: ISBN-0-521-47942-8)..

Hsu, W. (2009). College English textbooks for general purposes: A corpus-based analysis of lexical coverage. Electronic Journal of Foreign Language Teaching, 6(1), 42-62.

Lado, R. (1961). Language Testing: The Construction and Use of Foreign Language Tests. A Teacher's Book.

Lakshmi, M. (2012). Teaching lexis through comics: An exploratory study. Journal of Engineering, 2(9), 50-54.

Laufer, B. (1989). What percentage of text-lexis is essential for comprehension. Special language: From humans thinking to thinking machines, 316323.

Lewis, M. (1997). Pedagogical implications of the lexical approach. Second language vocabulary acquisition: A rationale for pedagogy, 255-270.

Lewis, M. (1993). The lexical approach (Vol. 1, p. 993). Hove: Language teaching publications.

Lewis, M. (2000) Teaching collocation: Further developments in the lexical approach. London: Language Teaching Publications.

McCarthy, M. J. (1984). A new look at vocabulary in EFL. Applied linguistics, 5(1), 12-22.

Meara, P. (1980). Vocabulary acquisition: A neglected aspect of language learning. Language Teaching, 13(3-4), 221-246. 
Nation, I. S. P. (2012, August). Measuring vocabulary size in an uncommonly taught language. In International Conference on Language Proficiency Testing in the Less Commonly Taught Languages (pp. 17-18).

Nunan, D. (2003). Practical English language teaching. New York: McGraw Hill/Contemporary.

Putri, Dara Puspa S. (2014). The vocabulary profile of UN (Ujian Nasional) of junior high school. (Thesis).Jakarta. Universitas Negeri Jakarta.

Rao, V. C. S. (2018). The importance of collocations in teaching of vocabulary. Journal for Research Scholars and Professionals of English Language Teaching, 7(2), 1-9.

$\mathrm{Wu}, \mathrm{H}$. Y., \& Hu, P. (2007). Major factors influencing reading comprehension: A factor analysis approach. Sino-US English Teaching, 4(9), 14-18.

\section{Site and Website}

Permendikbud no 19 (2005)[Online] Retrieved from https://kemenag.go.id/file/dokumen/PP1905.pdf (March 7, 2016).

Cobb, T. (2008). Web Vocabprofiler (Version 2.6)[Computer software]. Accessed 06/17/2016 from http://www. lextutor. ca/Vp. 

ENGLISH FRANCA : Academic Journal of English Language and Education Vol. 4, No. 1, 2020, IAIN Curup

P-ISSN 2580-3670, E-ISSN 2580-3689 